\title{
The universal overexpression of a cancer testis antigen hiwi is associated with cancer angiogenesis
}

\author{
SHUANG LI ${ }^{1 *}$, LI MENG ${ }^{1 *}$, CHANGHONG ZHU $^{2}$, LI WU $^{2}$, XIANGYANG BAI ${ }^{1}$, \\ JUNCHENG WEI $^{1}$, YUNPING LU ${ }^{1}$, JIANFENG ZHOU ${ }^{1}$ and DING MA ${ }^{1}$ \\ ${ }^{1}$ Cancer Biology Research Center, Tongji Hospital; ${ }^{2}$ Family Planning Research Institute, Tongji Medical College, \\ Huazhong University of Science and Technology, 1095 Jiefang Road, Wuhan 430030, P.R. China
}

Received August 3, 2009; Accepted November 16, 2009

DOI: $10.3892 /$ or_00000733

\begin{abstract}
The aim of this study was to determine whether the universal overexpression of hiwi is associated with cancer angiogenesis. The difference of mRNA expression in blood vessels derived from DLBCL and RLNH tissues was detected, and hiwi was overexpressed in tumor vessels of lymphoma. The hiwi expression in cell lines and tissues was measured by using RT-PCR and immuno-staining, as well as the Ang-2 and Tie-2 expressions in tissues. Hiwi was significantly expressed in cancer cell lines Hela, MCF-7, MDAMB-231, MDA-MB-435s, A2780, 111 and 113. Compared with that of chronic cervicitis (CC), hyperplasia of mammary glands (HMG), ovarian benign lesions (OBL) and endometrium benign lesions (EBL), the expression of hiwi, Ang-2 and Tie- 2 was increased significantly in uterine cervical cancer (UCC), breast carcinoma (BC), ovarian cancer (OC) and endometrial cancer $(\mathrm{EC})(\mathrm{P}<0.01)$. Additionally, the hiwi expression was positively correlated with Ang-2 in UCC, BC and $\mathrm{OC}$, and Tie-2 in OC. These results suggest that hiwi plays an important role in the oncogenesis and is a potential target for cancer angiogenesis.
\end{abstract}

\section{Introduction}

The angiogenesis plays a critical role in the progression and metastasis of cancer (1). Angiogenesis begins when a pinpoint colony of tumor cells expands to a size where the simple diffusion of nutrients is insufficient, and then new capillaries are elicited (2). Evidence was shown that tumor vessels are different from the normal ones at the molecular

Correspondence to: Dr Ding Ma or Dr Jianfeng Zhou, Cancer Biology Research Center, Tongji Hospital, 1095 Jiefang Road, Wuhan 430030, P.R. China

E-mail: dma@tjh.tjmu.edu.cn and dingma424@yahoo.com

E-mail: jfzhou@tjh.tjmu.edu.cn

${ }^{*}$ Contributed equally

Key words: hiwi, gene expression, cancer angiogenesis level (3-5). Therefore, the understanding of the molecular pathogenesis of tumor-specific endothelial aberrations in tumor vessels could stimulate the development of new therapeutic approaches that potently and specifically target angiogenesis.

However, the isolation of tumor vessels from the mixed tissues presents technical challenges. In the present study, we sought to develop a novel technique for analyzing the global gene expression in blood vessels obtained from primary tissues. The blood vessels of diffuse large B-cell lymphoma (DLBCL) and reactive lymph node hyperplasia (RLNH) were isolated by laser capture microdissection (LCM) from tissues fixed in situ, and then subjected to gene expression microarray analysis (GEMA). The hiwi gene was found to be specifically expressed in blood vessels of lymphoma.

The hiwi gene, the human homolog of the piwi family, is located in $12 \mathrm{q} 24.33$ and encodes a $98.5 \mathrm{kDa}$ protein (6). The hiwi protein contains a conserved architecture with a PAZ motif and Piwi motif $(7,8)$, and the hiwi gene was originally isolated from a human testis cDNA library (6), hinting of a potential role in human spermatogenesis (9). Because of the conserved functions of piwi genes in stem cell maintenance and germline development, it is of interest to study the role of hiwi in germ cell-derived tumors (6). Although hiwi gene was discovered years ago, so far, little research has been done on its biological properties and mechanisms except for the spermatogenesis field. The expression of hiwi has been also described in hematopoietic stem cells (HSC), suggesting that hiwi may be a developmental regulator in the maintenance of HSCs (9). Therefore, these data support the notion that hiwi may be a candidate gene that plays a potential role not only in the maintenance and proliferation of germ cells and stem cells, but also in the angiogenesis of malignancy development.

To date, few studies had been performed on the role of hiwi in cancer. We first employed the novel strategies to analyze the expression profile of the cancer blood vessels for differential genes, and identified that the hiwi transcript was specifically expressed in lymphoma-derived micro-vessels. Next, we explored that hiwi was universally expressed in many types of cancers, and the high expression of hiwi was closely related to the upregulation of angiogenesis relevant factors, such as Ang-2 and Tie-2. 


\section{Materials and methods}

Patients, tissues and cell lines. The fresh tissues, pathologically diagnosed as DLBCL $(n=2)$ and RLNH $(n=2)$, were collected from patients undergoing surgery at the Department of Homology, Tongji Hospital, Tongji Medical College of Huazhong University of Science and Technology.

The slides of paraffin-embedded tissues were obtained from the Department of Pathology at Tongji Hospital after pathological diagnosis, including hyperplasia of mammary glands (HMG) and breast carcinoma (BC) chronic cervicitis (CC) and uterine cervical cancer (UCC), endometrium benign lesion (EBL) and endometrial cancer (EC), ovarian benign lesion (OBL) and ovarian cancer (OC). The clinical and pathology data, such as age, diagnosis, disease stage and grade, were also collected at the same time.

Human cervical cancer cell lines Hela and Siha, human breast cancer cell lines MCF-7, MDA-MB-231and MDAMB-435s, human ovarial cancer cell line A2780 and human endometrial cancer cell lines 111 and 113 were obtained from American Type Culture Collection (ATCC, Manassas, VA, USA) and the European Collection of Cell Cultures (ECACC, Salisbury, UK), respectively. These cells were routinely cultured at $37^{\circ} \mathrm{C}$ in a humidified atmosphere of $5 \% \mathrm{CO}_{2}$ in RPMI-1640 or DMEM medium with $10 \%$ fetal calf serum (Gibco, USA).

LCM, total RNA isolation, RNA linear amplification and gene expression chip detection. After fixing in $\mathrm{Zn}$ fixation solution, the slides were subjected to immuno-staining with Dako rapid Envision ${ }^{\mathrm{TM}}$-HRP immuno-staining system (Dako Corp., Carpinteria, CA). Then the dissection of vessels were carried out through laser activation with an SL $\mu$ cut microscopic UV laser system [Molecular Machines \& Industries AG (MMI) (10)].

Total RNA of the vessels was isolated by using RNAeasy ${ }^{\circledR}$ Micro Kit (Qiagen, Hilden, Germany) according to the manufacturer's instructions. Because of the small amount of starting total RNA, the non-bias linear amplification was performed with MessageAmp-aRNA kit (Ambion, Austin, TX) in order to obtain sufficient amounts of labeled antisense RNA (aRNA) for micoarray analysis $(11,12)$. The quality of total RNA and aRNA was monitored with the RNA 6000 Nano LabChip Kit (Agilent Technologies, Boeblingen, Germany), and the fragmentation of cRNA was also detected quantitatively and qualitatively before hybridization. The fragmented cRNA was hybridized onto the human genome U133 plus 2.0 arrays (Affymetrix, Santa Clara, CA). The arrays with hybridized probes were scanned with the Affymetrix ${ }^{\circledR}$ GeneChip Scanner 3000 and the images were analyzed with GCOS software (Affymetrix).

Total RNA isolation and the expression of hiwi mRNA. Human cancer cell lines Hela, Siha, MCF-7, MDA-MB-231, MDA-MB-435s, A2780, 111 and 113 cultured in 6-well plates were harvested when they reached $80 \%$ confluence, respectively.

Total RNA was isolated from the different cell lines by using TRIzol reagent (Invitrogen, Carlsbad, CA) according to the manufacturer's instructions, and the RT mixture was incubated at $75^{\circ} \mathrm{C}$ for 5 min followed by quick-chill on ice, then at $42^{\circ} \mathrm{C}$ for $60 \mathrm{~min}$. A fixed amount of RT products (one tenth of RT products) and $0.5 \mu \mathrm{mol} / 1$ upper-lower primers were co-amplified at a final concentration of $1 \mathrm{X}$ PCR buffer, $50 \mu \mathrm{mol} / 1 \mathrm{dNTPs}, 1 \mathrm{U}$ Taq DNA polymerase (Ferment, USA) in a total volume of $50 \mu 1$. The amplification profile was: denaturation at $94^{\circ} \mathrm{C}$ for $30 \mathrm{sec}$, primer annealing at $58^{\circ} \mathrm{C}$ for $40 \mathrm{sec}$, and extension at $72^{\circ} \mathrm{C}$ for $30 \mathrm{sec}$. Hiwi upper primer: 5'-CTGTGTACAGATTGCCCTACCC-3' and hiwi lower primer: 5'-GCAGACTTTGAGCCCATCTACCAG-3'. The housekeeping gene $\beta$-actin was used as an internal quantity control. The predicted sizes for hiwi and B-actin PCR products were 312 and $416 \mathrm{bp}$, respectively.

The expression of hiwi, Ang-2 and Tie-2 proteins. Cancer cells of Hela, Siha, MCF-7, MDA-MB-231, MDA-MB-435s, A2780, 111 and 113 on the glass coverslips were fixed in a $1: 1$ mixture of $100 \%$ ethanol and cold acetone at $4^{\circ} \mathrm{C}$ for $15 \mathrm{~min}$ and then air-dried. After incubation in $1 \%$ Triton $\mathrm{X}-100$ for $15 \mathrm{~min}$, the slides were incubated with $1 \%$ bovine serum albumin (BSA) at room temperature for $30 \mathrm{~min}$ to reduce non-specific binding. Then, the slides were incubated with a 1:500 goat polyclonal anti-hiwi antibody (Santa Cruz Biotechnology, CA, USA) at $37^{\circ} \mathrm{C}$ for $1 \mathrm{~h}$. After the slides were treated with a fluorescein isothiocyanate-conjugated rabbit anti-goat IgG, they were mounted in PI solution (Sigma, USA). Finally, the morphology of cancer cells was observed with a confocol microscope system OLFV-32U2/ XE-3 (Olympus, Japan).

The tissue sections of CC, UCC, HMG, BC, OBL, OC, EBL and EC were deparaffinized and hydrated in serial dilutions of alcohol, and the sections were microwaved in 40 mM Borate buffer ( $\mathrm{pH}$ 8.2) supplemented with 1 mM EDTA and $1 \mathrm{mM} \mathrm{NaCl}$ for $20 \mathrm{~min}$ for antigen retrieval $(13,14)$. Slides were treated with $3 \% \mathrm{H}_{2} \mathrm{O}_{2}$ for $10 \mathrm{~min}$ to quench endogenous peroxidase activity, then, immersed in $1 \% \mathrm{BSA}$ at room temperature for $30 \mathrm{~min}$. The tissues were incubated with a goat polyclonal anti-hiwi antibody (1:600 dilution), a rat anti-Ang-2 polyclonal antibody and a rat anti-Tie-2 polyclonal antibody (Santa Cruz Biotechnology, 1:150 dilutions) overnight at $4^{\circ} \mathrm{C}$, respectively. After rinsing, the slides were further incubated with a secondary antibody for an additional $30 \mathrm{~min}$. The chromagen detection was developed with 3'diaminobenzidine (Jinqiao, Beijing, China) for $5 \mathrm{~min}$, and the slides were counterstained with Meyer's hematoxylin, dehydrated, and mounted with Canada balsam for examination.

Evaluation of results of immunohistochemical staining. The Sinicrope et al scoring method was applied to evaluate both the staining intensity and the proportion of the stained cells (15). The staining intensity was sub-classified as follows: 1 , weak; 2, moderate; or 3, strong. The percentage of the total number of positive cells was quantified, and then assigned into one of the following five categories: $0,<5 \% ; 1,5-25 \%$; $2,26-50 \% ; 3,51-75 \%$; and $4,>75 \%$. Next, the positive percentage and the staining intensity were multiplied to generate the immunoreactivity score (IS) for each specimen. Each lesion was separately examined and scored by two pathologists. The cases with discrepant scores were discussed to obtain a consensus. 

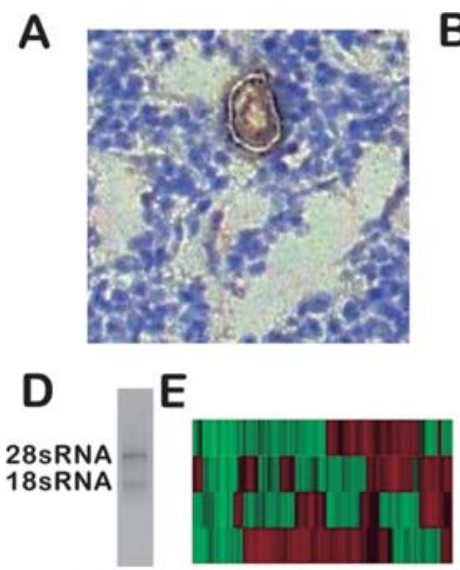

B

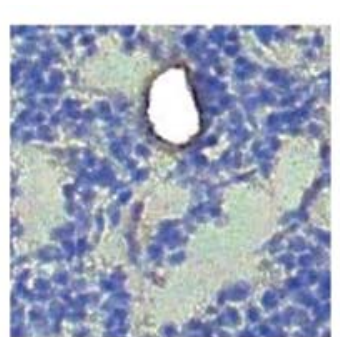

C

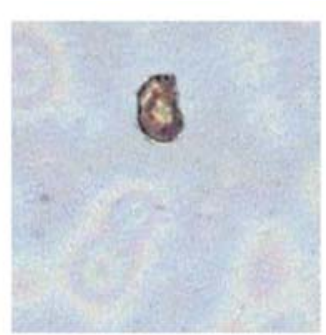

$\mathbf{F}$
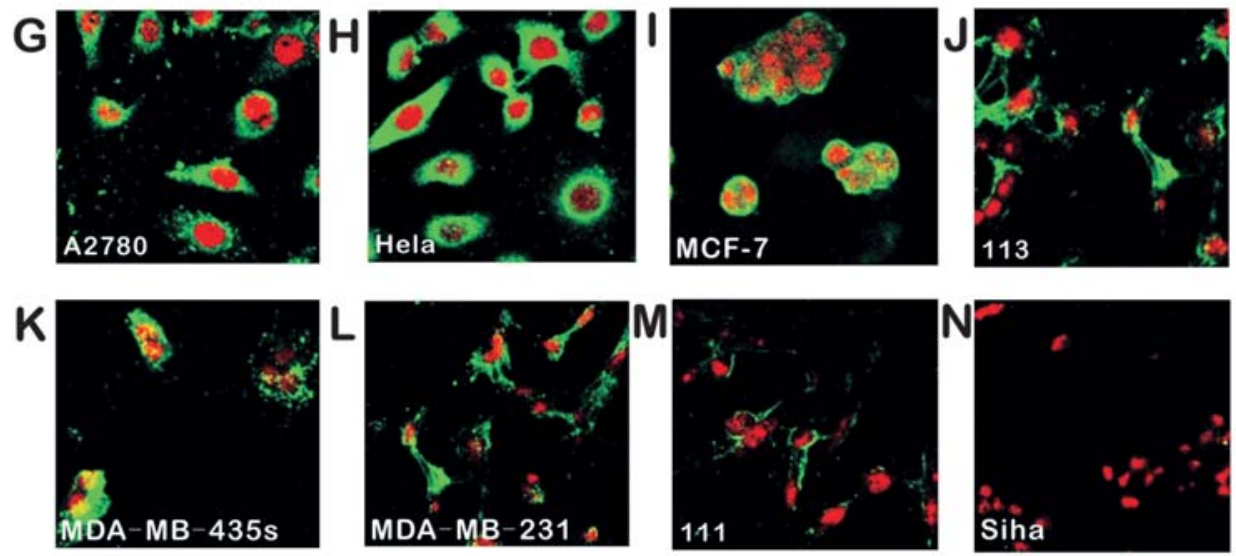

Figure 1. (A-C) The labeled vessels in DLBCL and RLNH tissues were captured efficiency by using LCM. (D) The ratios of 28S to 18S rRNA bands of vessels were 2:1. (E) GEMA. (F) The hiwi mRNA expression in cancer cell lines by using RT-PCR. (G-N) The hiwi protein expression in cancer cell lines by using immuno-fluorescence assay.

Statistical analysis. SPSS 13.0 statistical software was used to perform statistical analysis. The Fisher's exact test, Pearson's $\chi^{2}$ test, ANOVA SNK test and Nemenyi-Wilcoxon-Wilcox test were used to assess the differences. Spearman's rank correlation was used to determine whether there was a positive or negative correlation. The level of $\mathrm{P}<0.05$ was considered to be statistically significant.

\section{Results}

Hiwi is overexpressed in the lymphoma-derived microvessels. The labeled vessels were readily identified under microscopy and harvested by using LCM technique. As seen in Fig. 1A-C, the microvessels in DLBCL and RLNH tissues were labeled with brown staining to improve the capture efficiency of LCM. The ratios of $A_{260}$ to $A_{280}$ values of the RNA prepared in vessels are shown in the range of 1.8-2.0. The integrity of total RNA was determined and based on the ratio of $28 \mathrm{~S}$ to 18S rRNA bands, which were 2:1 (Fig. 1D). Therefore, the intact mRNA in vessels was successfully isolated from the fresh samples. Hybridization results revealed that 80 genes were upregulated and 72 genes were downregulated in DLBCL. Of these candidates, hiwi continually demonstrated to be positive in DLBCL tissues, but negative in RLNH tissues (Fig. 1E). Therefore, the hiwi gene was chosen for further analysis.
The hiwi gene is expressed in many types of cancer cell lines. The special mRNA expression of hiwi was positively detected in 7 cancer cell lines except for the cervical cell line Siha. The levels of hiwi mRNA in A2780, Hela, MCF-7 and 113 cell lines were high, while the expressions in 111 , MDA-MB-231 and MDA-MB-435s cell lines were weaker (Fig. 1F). The PCR products were confirmed by sequencing. Similarly, as shown in Fig. 1G-L, it was clear that hiwi protein was also detectable in the cytoplasm of 7 cell lines, especially in A2780, Hela and MCF-7 cell lines.

The expression levels of hiwi, Ang-2 and Tie-2 proteins are detected in the different tissues. The expressions of hiwi and angiogenesis relevant factors Ang-2 and Tie-2 in various carcinomas and non-carcinomas tissues were analyzed by using immunohistochemistry.

In case of hiwi, although the expression was also found in cytoplasm of the matched non-carcinoma, the levels were rather low. However, the aberrant expression of hiwi was frequently observed in carcinoma. Compared with those of $\mathrm{CC}, \mathrm{HNC}, \mathrm{OBL}$ and EBL, the levels of hiwi were strikingly higher in UCC, BC, OC and EC with statistical significance, respectively (Figs. 2 and 3) $(\mathrm{P}<0.01)$. The hiwi levels in the early stage cancer were obviously increased in comparison to those in the matched benign lesions $(\mathrm{P}<0.05)$. While there was no difference in the hiwi levels between the early-stage 


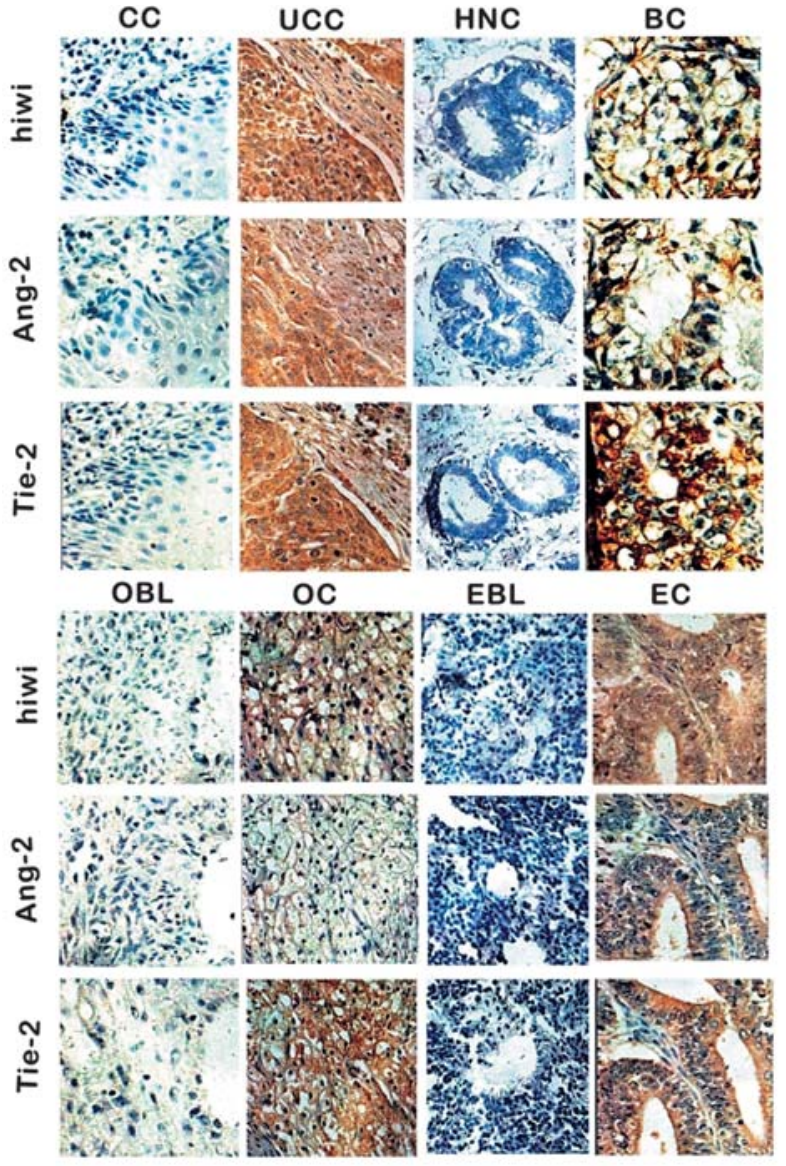

Figure 2. The hiwi protein expression in different tissues by using immunohistochemistry. CC, chronic cervicitis; UCC, uterine cervical cancer; HMG, mammary glands; $\mathrm{BC}$, breast carcinoma; OBL, ovarian benign lesion; OC, ovarian cancer; EBL, endometrial benign lesion; EC, endometrial cancer.

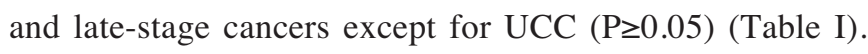
We further analyzed the frequency of high levels with the IS higher than 3 in neoplastic versus non-neoplastic tissues. The high cytoplasmic expression of hiwi was rare in the matched non-carcinoma lesions, but the rates were much higher in UCC, BC, OC and EC $(\mathrm{P}<0.01)$ (Table II).

Similar to hiwi, both Ang-2 and Tie-2 exhibited cyplasmic expression pattern. The expressions of Ang-2 and Tie-2 were generally low in overall matched benign lesions, however, the Ang-2 and Tie-2 levels were higher in various carcinomas $(\mathrm{P}<0.01)$ (Figs. 2 and 3). On the other hand, compared with those of the matched benign non-cancer lesions, Ang-2 and Tie-2 levels were obviously upregulated in the early stage cancers $(\mathrm{P}<0.05)$, but there was no difference between the early-stage and the late-stage cancers $(\mathrm{P} \geq 0.05)$. The rates of Ang- 2 and Tie- 2 with the IS higher than 3 were very low in the matched benign lesions, and much higher in several carcinoma tissues except for OC (Table II).

The hiwi expression is correlated with angiogenesis-relevant factors Ang-2 and Tie-2. The expression of hiwi was positively correlated with the Ang-2 expression in UCC $(\varrho=0.7696$, $\mathrm{P}=0.0013)$, $\mathrm{BC}(\mathrm{\varrho}=0.9087, \mathrm{P}=0.0018)$ and $\mathrm{OC}(\mathrm{\varrho}=0.7225$, $\mathrm{P}=0.0429)$. Moreover, a positive correlation with cancer angiogenesis assessed by Tie-2 was observed for hiwi in OC $(\mathrm{Q}=0.7554, \mathrm{P}=0.0302)$ (Table III).

\section{Discussion}

So far, only a very limited number of studies support a role of a cancer testis antigen hiwi in cancer $(9,16)$. Furthermore, the correlation between hiwi and angiogenesis in cancers was

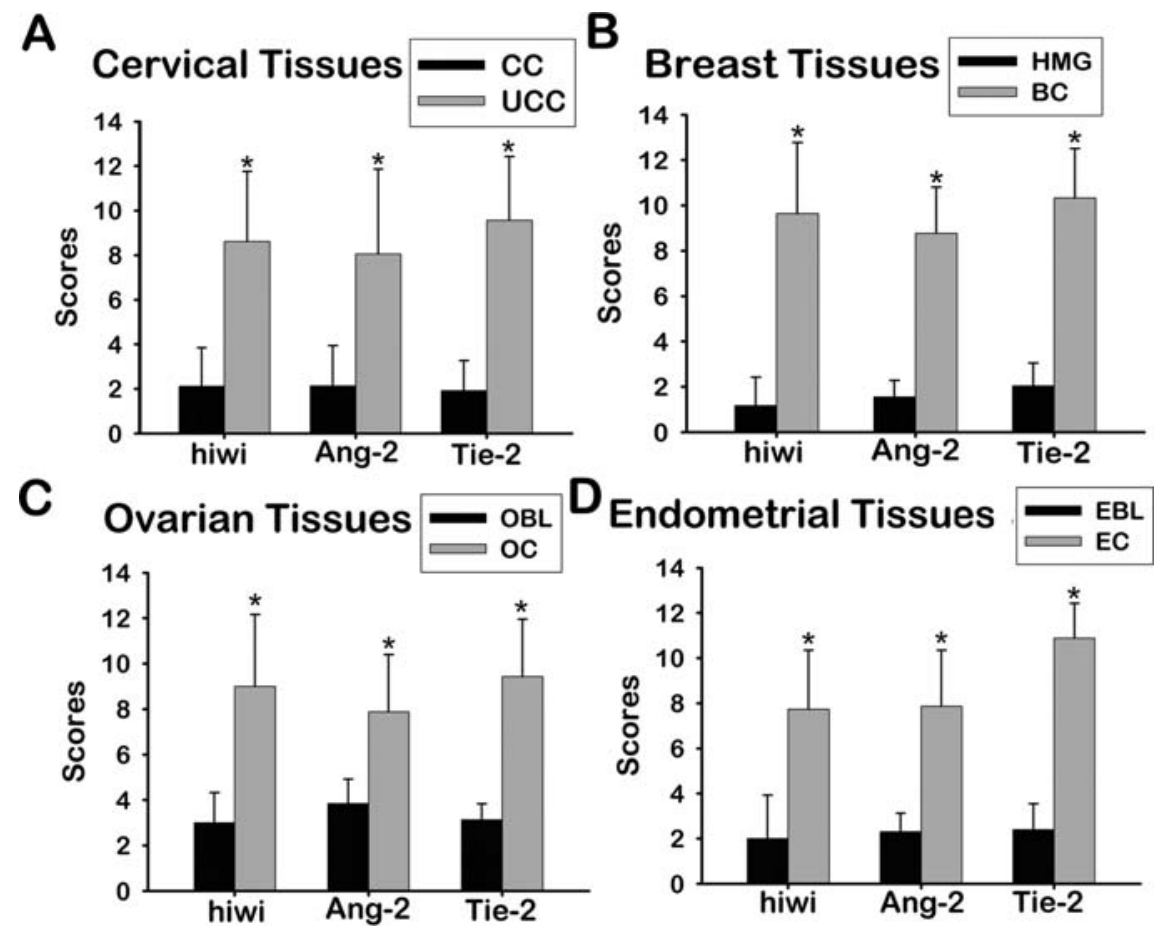

Figure 3. The means of immunoreactivity scores (IS) of hiwi, Ang-2 and Tie-2 in different tissues. (A) Cervical tissues, (B) breast tissues, (C) ovarian tissues and (D) endometrial tissues. 
Table I. The expressive difference of hiwi, Ang-2 and Tie-2 in the different non-cancer and cancer tissues.

\begin{tabular}{|c|c|c|c|c|c|c|c|c|}
\hline \multirow[b]{2}{*}{ Subjects } & \multirow[b]{2}{*}{ Factor } & \multicolumn{2}{|c|}{$\mathrm{N}$ vs. E } & & \multicolumn{2}{|c|}{ E vs. L } & \multirow[b]{2}{*}{ Chi-value } & \multirow[b]{2}{*}{ P-value } \\
\hline & & Chi-value & P-value & & Chi-value & P-value & & \\
\hline \multirow[t]{3}{*}{ Cervix } & hiwi & 9.1096 & 0.0105 & \multirow{3}{*}{$\mathrm{L}=\mathrm{E}>\mathrm{N}$} & 8.9802 & 0.0112 & 46.0768 & $<0.0001^{\mathrm{a}}$ \\
\hline & Ang-2 & & & & & & $\mathrm{F}=16.47$ & $<0.0001^{\mathrm{b}}$ \\
\hline & Tie-2 & 10.3961 & 0.0055 & & 0.9536 & 0.6208 & 22.6434 & $<0.0001^{\mathrm{a}}$ \\
\hline \multirow[t]{3}{*}{ Breast } & hiwi & 8.7398 & 0.0127 & \multirow{3}{*}{$\mathrm{L}=\mathrm{E}>\mathrm{N}$} & 0.4395 & 0.8027 & 19.0100 & $<0.0001^{\mathrm{a}}$ \\
\hline & Ang-2 & & & & & & $\mathrm{F}=49.75$ & $<0.0001^{\mathrm{b}}$ \\
\hline & Tie-2 & 5.4881 & 0.0443 & & 0.0702 & 0.9655 & 13.3845 & $0.0012^{a}$ \\
\hline \multirow[t]{3}{*}{ Ovary } & hiwi & & & $\mathrm{L}=\mathrm{E}>\mathrm{N}$ & & & $F=10.65$ & $0.0007^{b}$ \\
\hline & Ang-2 & & & $\mathrm{L}=\mathrm{E}>\mathrm{N}$ & & & $\mathrm{F}=4.44$ & $0.0305^{\mathrm{b}}$ \\
\hline & Tie-2 & & & $\mathrm{L}=\mathrm{E}>\mathrm{N}$ & & & $\mathrm{F}=15.82$ & $0.0003^{\mathrm{b}}$ \\
\hline \multirow[t]{3}{*}{ Endometrium } & hiwi & & & $\mathrm{L}=\mathrm{E}>\mathrm{N}$ & & & $\mathrm{F}=13.01$ & $0.0004^{b}$ \\
\hline & Ang-2 & & & $\mathrm{L}=\mathrm{E}>\mathrm{N}$ & & & $\mathrm{F}=12.29$ & $0.0020^{\mathrm{b}}$ \\
\hline & Tie-2 & 6.7517 & 0.0342 & & 0.0088 & 0.9956 & 9.2130 & $0.0100^{a}$ \\
\hline
\end{tabular}

$\mathrm{N}$, non-cancer; E, early-stage cancer; L, late-stage cancer. ${ }^{\mathrm{a}} \mathrm{AVONO}$ SNK test; ${ }^{\mathrm{b}}$ Nemenyi-Wilcoxon-Wilcox test $(\alpha=0.05)$.

Table II. The expression levers of hiwi, Ang-2 and Tie-2 in the different tissues.

\begin{tabular}{|c|c|c|c|c|c|c|c|}
\hline \multirow[b]{2}{*}{ Subjects (n) } & \multirow[b]{2}{*}{ Factor } & \multicolumn{2}{|c|}{ Non-cancer } & \multicolumn{2}{|c|}{ Cancer } & \multirow[b]{2}{*}{ Chi-value } & \multirow[b]{2}{*}{ P-value } \\
\hline & & Low $(\%)$ & High $(\%)$ & Low (\%) & $\operatorname{High}(\%)$ & & \\
\hline Cervix & hiwi & $18(82.0)$ & $7(18.0)$ & $3(7.5)$ & $37(92.5)$ & 29.2658 & $<0.0001^{\mathrm{a}}$ \\
\hline$(\mathrm{Nnc}=25)$ & Ang-2 & $21(84.0)$ & $4(16.0)$ & $8(20.0)$ & $32(80.0)$ & 25.5019 & $<0.0001^{\mathrm{a}}$ \\
\hline$(\mathrm{Nc}=40)$ & Tie-2 & $19(76.0)$ & $6(24.0)$ & $4(10.0)$ & $36(90.0)$ & 29.3106 & $<0.0001^{\mathrm{a}}$ \\
\hline Breast & hiwi & $11(84.6)$ & $2(15.4)$ & $0(0.0)$ & $14(100.0)$ & 19.9904 & $<0.0001^{\mathrm{a}}$ \\
\hline$(\mathrm{Nnc}=13)$ & Ang-2 & $8(61.5)$ & $5(38.5)$ & $1(7.2)$ & $13(92.8)$ & & $0.0038^{\mathrm{b}}$ \\
\hline$(\mathrm{Nc}=14)$ & Tie-2 & $10(76.9)$ & $3(23.1)$ & $3(21.4)$ & $11(78.6)$ & & $0.0039^{b}$ \\
\hline Ovary & hiwi & $5(71.4)$ & $2(28.6)$ & $1(8.3)$ & $11(91.7)$ & & $0.0093^{\mathrm{b}}$ \\
\hline$(\mathrm{Nnc}=7)$ & Ang-2 & $5(71.4)$ & $2(28.6)$ & $3(25.0)$ & $9(75.0)$ & & $0.0739^{\mathrm{b}}$ \\
\hline$(\mathrm{Nc}=12)$ & Tie-2 & $4(57.1)$ & $3(42.9)$ & $2(16.7)$ & $10(83.3)$ & & $0.1287^{\mathrm{b}}$ \\
\hline Endometrium & hiwi & $5(62.5)$ & $3(37.5)$ & $1(10.0)$ & $9(90.0)$ & & $0.0302^{\mathrm{b}}$ \\
\hline$(\mathrm{Nnc}=8)$ & Ang-2 & $5(62.5)$ & $3(37.5)$ & $1(10.0)$ & $9(90.0)$ & & $0.0302^{\mathrm{b}}$ \\
\hline$(\mathrm{Nc}=10)$ & Tie-2 & $6(75.0)$ & $2(25.0)$ & $1(10.0)$ & $9(90.0)$ & & $0.0088^{\mathrm{b}}$ \\
\hline
\end{tabular}

Nnc, number of non-cancer; Nc, number of cancer. ${ }^{\text {Pearson's }} \chi^{2}$ tests; ${ }^{b}$ Fisher's exact test.

almost unknown. Although the exact function and biological effects of hiwi remain unknown, the evidence that the overexpression of hiwi might be a key element in stem cell division and caused seminomatous malignancy development suggested that hiwi may be involved in carcinogenesis $(6,9,16)$. To our knowledge, this was the first observation that hiwi was universally upregulated in many types of cancers and associated with tumor vessels and angiogeneic factors Ang-2 and Tie-2.

The most comprehensive of our hybridization outcome raised the hypothesis that hiwi enriched in tumor vessels might be associated with carcinogenesis and tumor angiogenesis. To validate the microarray data, the hiwi expression was generally measured in several cancer cell lines and tissues, including cervical, breast, ovarian and endometrial cancer.
In brief, the mRNA and protein of hiwi were found in 7 cancer cell lines, especially in A2780, Hela and MCF-7. Moreover, the hiwi protein expression was obviously increased in $\mathrm{UCC}, \mathrm{BC}, \mathrm{OC}$ and $\mathrm{EC}$ tissues $(\mathrm{P}<0.05)$ and the rates of high expression were also significantly improved in cancers $(\mathrm{P}<0.01)$. Additionally, the hiwi levels in the early-stage cancers were dramatically increased in comparison to those in the matched benign lesions $(\mathrm{P}<0.05)$, while there was no difference in the hiwi levels between the early-stage and latestage cancers except for UCC $(\mathrm{P} \geq 0.05)$. The present study has clearly demonstrated that the universal overexpression of hiwi was closely correlated with a malignant state. The expression of hiwi was not correlated with the clinical stages except for UCC. 
Table III. The correlation of hiwi, Ang-2 and Tie-2 in the different cancer tissues.

\begin{tabular}{|c|c|c|c|c|}
\hline Subjects & Factor & hiwi & Ang-2 & Tie-2 \\
\hline \multirow[t]{6}{*}{ UCC } & hiwi & 1.0000 & & \\
\hline & & 0.0000 & & \\
\hline & Ang-2 & 0.7696 & 1.0000 & \\
\hline & & 0.0013 & 0.0000 & \\
\hline & Tie-2 & 0.3239 & 0.40268 & 1.0000 \\
\hline & & 0.2586 & 0.1534 & 0.0000 \\
\hline \multirow[t]{6}{*}{$\mathrm{BC}$} & hiwi & 1.0000 & & \\
\hline & & 0.0000 & & \\
\hline & Ang-2 & 0.9087 & 1.0000 & \\
\hline & & 0.0018 & 0.0000 & \\
\hline & Tie-2 & 0.6620 & 0.6325 & 1.0000 \\
\hline & & 0.0737 & 0.0924 & 0.0000 \\
\hline \multirow[t]{6}{*}{ OC } & hiwi & 1.0000 & & \\
\hline & & 0.0000 & & \\
\hline & Ang-2 & 0.7225 & 1.0000 & \\
\hline & & 0.0429 & 0.0000 & \\
\hline & Tie-2 & 0.7554 & 0.5564 & 1.0000 \\
\hline & & 0.0302 & 0.1521 & 0.0000 \\
\hline \multirow[t]{6}{*}{$\mathrm{EC}$} & hiwi & 1.0000 & & \\
\hline & & 0.0000 & & \\
\hline & Ang-2 & 0.3078 & 1.0000 & \\
\hline & & 0.6144 & 0.0000 & \\
\hline & Tie-2 & -0.7404 & -0.8660 & 1.0000 \\
\hline & & 0.1524 & 0.0577 & 0.0000 \\
\hline
\end{tabular}

Correlation significant at the 0.05 level (2-tailed). Spearman correlation coefficients

The literature regarding the biological properties of hiwi in cancer angiogenesis is rare. Ang-2, believed to antagonize the stabilizing action of Ang-1, binds with the endothelial cell tyrosine kinase receptor Tie-2 (17). It has been revealed that the low Ang-1/Ang-2 gene expression ratio and the high Tie-2 gene expression are significantly associated with the high MVD (18). With the presence of VEGF in cancer tissues, Ang-2 seems to be the strengthening factor for the initiation of angiogenesis and for vascular sprouting $(19,20)$. The current findings indicated that hiwi was overexpressed in the tumor vessels. They also revealed that hiwi was significantly, positively correlated with not only Ang-2 levels in UCC, BC and OC, but also Tie-2 levels in OC $(\mathrm{P}<0.05)$. Therefore, hiwi may be a potential target involved in tumor angiogenesis. The implications of these findings need to be clarified, and should be examined in a future study with a larger number of patients and more homogeneous characteristics.

In summary, these results suggest that hiwi may play an important role in oncogenesis and is a potential angiogenesis target for cancer biotherapy. Further investigation is necessary to lead to development of a new molecular target therapy for epithelial cancers based on the present results.

\section{Acknowledgements}

Grant support: '973' Program of China (No. 2009CB521800), the grants from the National Natural Science Foundation of China (No. 30672227; 30770913; 30628029; 30500596; 30600667) and the Innovation Funding from Huazhong University of Science and Technology (No. HF-05-035-07540). We are grateful to Professor Xiong Chengliang, Dr Liu Yaowei, Dr Tian Yonghong and Dr Li Honggang for their excellent technical assistance and advice.

\section{References}

1. Carmeliet P: Angiogenesis in health and disease. Nat Med 96: 53-60, 2003.

2. Folkman J: Tumor angiogenesis: therapeutic implications. N Engl J Med 285: 1182-1186, 1971

3. Hida K, Hida Y, Amin DN, Flint AF, Panigrahy D, Morton CC and Klagsbrun M: Tumor-associated endothelial cells with cytogenetic abnormalities. Cancer Res 64: 8249-8255, 2004.

4. Streubel B, Chott A, Huber D, Exner M, Jäger U, Wagner O and Schwarzinger I: Lymphoma-specific genetic aberrations in microvascular endothelial cells in B-cell lymphomas. N Engl J Med 351: 250-259, 2004.

5. St Croix B, Rago C, Velculescu V, et al: Genes expressed in human tumor endothelium. Science 289: 1197-1202, 2000.

6. Qiao D, Zeeman AM, Deng W, Looijenga LH and Lin H: Molecular characterization of hiwi, a human member of the piwi gene family whose overexpression is correlated to seminomas. Oncogene 21: 3988-3999, 2002.

7. Cerutti L, Mian N and Bateman A: Domains in gene silencing and cell differentiation proteins: the novel PAZ domain and redefinition of the Piwi domain. Trends Biochem Sci 25: 481-482, 2000.

8. Yan KS, Yan S, Faroog A, Han A, Zeng L and Zhou MM: Structure and conserved RNA binding of the PAZ domain. Nature 426: 468-474, 2003.

9. Sharma AK, Nelson MC, Brandt JE, Wessman M, Mahmud N, Weller KP and Hoffman R: Human CD34(+) stem cells express the hiwi gene, a human homologue of the Drosophila gene piwi. Blood 97: 426-434, 2001.

10. Kalantari M, Garcia-Carranca A, Morales-Vazquez CD, et al: Laser capture microdissection: molecular analysis of tissue. Science 278: 1481-1483, 1997.

11. Spiess AN, Mueller N and Ivell R: Amplified RNA degradation in T7-amplification methods results in biased microarray hybridizations. BMC Genomics 4: 44, 2003

12. Dumur CI, Garrett CT, Archer KJ, et al: Evaluation of a linear amplification method for small samples used on high-density oligonucleotide microarray analysis. Anal Biochem 331: 314$321,2004$.

13. Kim SH, Kook MC and Song HG: Optimal conditions for the retrieval of CD4 and CD8 antigens in formalin-fixed, paraffinembedded tissues. J Mol Histol 35: 403-408, 2004.

14. Kim SH, Kook MC and Song HG: Evaluation of antigen retrieval buffer systems. J Mol Histol 35: 409-416, 2004.

15. Sinicrope FA, Ruan SB, Cleary KR, Stephens LC, Lee JJ and Levin B: Levin, bcl-2 and p53 oncoprotein expression during colorectal tumorigenesis. Cancer Res 55: 237-241, 1995.

16. Liu X, Sun Y, Guo J, et al: Expression of hiwi gene in human gastric cancer was associated with proliferation of cancer cells. Int J Cancer 15: 1922-1929, 2006.

17. Davis S, Aldrich TH, Jones PF, et al: Isolation of angiopoietin-1, a ligand for the TIE2 receptor, by secretion-trap expression cloning. Cell 87: 1161-1169, 1996.

18. Hata K, Nakayama K, Fujiwaki R, et al: Expression of the angopoietin-1, angopoietin-2, Tie2, and vascular endothelial growth factor gene in epithelial ovarian cancer. Gynecol Oncol 93: 215-212, 2004.

19. Maisonpierre PC, Suri C, Jones PF, et al: Angiopoietin-2, a natural antagonist for Tie 2 that disrupts in vivo angiogenesis. Science 277: 48-50, 1997.

20. Witzenbichler B, Maisonpierre PC, Jones P, Yancopoulos GD and Isner JM: Chemotactic properties of angiopoietin-1 and -2, ligands for the endothelial-specific receptor tyrosine kinase Tie2. J Biol Chem 17: 18514-18521, 1998. 